\title{
Constante evolução da Tecnologia da Informação exige novo perfil dos jovens profissionais
}

\author{
Constant evolution of information technology requires \\ new profile for young professionals
}

Elena Mariele Bini

Luis Mauricio Martins de Resende

Rosemari Monteiro Castilho Foggiatto Silveira

\begin{abstract}
Resumo
$\mathrm{O}$ atual modelo de sociedade exige a formação de cidadãos plenos, críticos e conscientes de suas responsabilidades, atuantes no mundo do trabalho com iniciativa, demonstrando atitudes criativas e preparados para propor soluções para resolução dos mais diferentes problemas. Tendo em vista a necessidade da formação de jovens empreendedores para o mundo do trabalho, é necessário possibilitar no espaço escolar, momentos para o estímulo ao reconhecimento de características empreendedoras necessárias para atuação profissional. $\mathrm{O}$ artigo aqui apresentado faz referência a proposta metodológica (Info@Empreendedor), elaborada para aplicação no curso Técnico em Informática, modalidade integrado, sendo suas atividades destinadas a quarta série do referido curso. Um projeto piloto foi realizado durante o primeiro semestre de 2008, seus resultados demonstram que tal proposta metodológica pode estimular características empreendedoras nos alunos e também contribuir com a sociedade em relação a desmistificação de conceitos relacionados a tecnologia da informação e empresas de pequeno porte.
\end{abstract}

Palavras-chave: empreendedorismo, informática, proposta metodológica.

\begin{abstract}
The current model of society requires the formation of full citizens, critical and conscious of their responsibilities, acting in the world of work and initiative, demonstrating creative attitudes and prepared to offer solutions to solve many different problems. Have in view of the needed for training of young entrepreneurs to work, it necessary to possible in school environment, time to stimulate the recognition of entrepreneurial characteristics necessary for professional practice. The article presented here refers to a methodological proposal (Info@Entrepreneur) developed for implementation in the course in Computer Technician, integrated mode, and its activities are realizing with fourth grade of the course. A pilot project was realized during the first semester of 2008 , the results showed was that this
\end{abstract}


methodological proposal can stimulate entrepreneurial characteristics in students and also contribute to the society on suspicion of concepts related to information technology and small business

Keywords: entrepreneurial, informatics, methodological proposal.

\section{Introdução}

Aumento da competição e busca de vantagem competitiva são características do modelo de mercado atual, amplamente estratificado, onde empresas buscam na TI (Tecnologia da Informação) meios para atingir almejado sucesso. A estratificação do mercado apresenta não só exigências diferenciadas em relação a TI, mas também níveis culturais desiguais. Assim, enquanto em grandes empresas é corriqueiro encontrar equipes próprias de TI formada por funcionários treinados, financiamento para pesquisa e desenvolvimento, em empresas de pequeno porte verifica-se, em muitos casos, poucos funcionários, recursos financeiros limitados e não existência de equipe de TI própria.

Pesquisa relatada em Bini (2007), apresenta diferentes cenários, não satisfatórios, da aplicação da $\mathrm{TI}$ em micro e pequenas empresas, como: (i) o empresário que acredita que as ferramentas de $\mathrm{TI}$ ainda não são essenciais para sua empresa e (ii) os empresários que reconhecem a importância da $\mathrm{Tl}$, especificamente do computador em sua empresa, porém, ao adquirir tal equipamento acreditaram já estar satisfazendo todas as necessidades da organização, e hoje percebem que faltam recursos como softwares e treinamento para funcionários, mas acabam por deixar essas necessidades em segundo plano. Os resultados apresentados na referida pesquisa remetem à reflexões acerca do importante papel que professores e estudantes de informática têm a desenvolver. Muitos conceitos precisam ser desmistificados. Faz-se necessário apresentar aos micro e pequenos empresários a TI como recurso essencial para o alcance de vantagem competitiva e não motivo para insatisfação. Dessa forma, esse trabalho apresenta as atividades realizadas e os resultados obtidos com a realização de um projeto piloto durante as aulas do curso Técnico em Informática, modalidade integrado, visando o estímulo ao empreendedorismo afim de formar jovens profissionais capazes de fortalecer a cultura da informática e capazes de atuar de forma ética e responsável na sociedade.

\section{Educação Empreendedora em Informática}

A proposta para educação empreendedora apresentada nesse trabalho demonstra a preocupação em se trabalhar conceitos empreendedores com educandos do curso Técnico em 
Informática, visando prepará-los para a atuação no mundo do trabalho como intraempreendedores, empreendedor proprietário de uma empresa, empreendedor autônomo, ou ainda, como tecnoempreendedor. Tal proposta busca contribuir com a formação de jovens capazes de fortalecer a cultura da informática, atuando com base em questões éticas e responsáveis, a fim de esclarecer dúvidas, desmistificar conceitos, apresentar a informática como recurso essencial para a resolução de metas e alcance dos objetivos empresariais, visando a melhoria na qualidade de vida de empresários e funcionários.

Ao buscar envolver os alunos em uma atmosfera empreendedora fez-se necessário o resgate de propostas para a educação empreendedora já elaboradas, sendo elas:

Oficina do Empreendedor (OE): criada por Fernando Dolabela, destinada especialmente a formação de universitários para a atuação em ambientes empresariais;

Pedagogia Empreendedora (PE): também proposta por Fernando Dolabela, destinada a formação de crianças do ensino fundamental e jovens do ensino médio, visando formar um indivíduo que atue colocando em prática os conceitos empreendedores trabalhados em toda a situação que os exija;

Projeto Junior Achievement (JA): projeto que tem sua origem nos Estados Unidos e tem por objetivo disseminar conceitos empreendedores, visando estimular características empreendedoras nos jovens. O quadro 1, foi elaborado por (Pires, 2006) e apresenta as principais características das três propostas.

Quadro 1: Características das propostas Oficina do Empreendedor (OE), Pedagogia Empreendedora (PE) e Programa Junior Achievement (JA)

(Fonte: Pires, 2006)

\begin{tabular}{|c|c|c|c|}
\hline $\begin{array}{l}\text { Caracterí } \\
\text { sticas }\end{array}$ & $\mathrm{OE}$ & PE & JA \\
\hline $\begin{array}{l}\text { Objetivos } \\
\text { declarados }\end{array}$ & $\begin{array}{l}\text { - Possibilitar } \\
\text { a abertura de uma } \\
\text { empresa }\end{array}$ & $\begin{array}{l}\text { - Preparar } \\
\text { alunos para serem } \\
\text { empreendedores em } \\
\text { qualquer atividade } \\
\text { que escolherem } \\
\text { - Desenvolver } \\
\text { o protagonismo do } \\
\text { educando }\end{array}$ & $\begin{array}{l}\text { - Educação } \\
\text { prática em economia } \\
\text { e negócios }\end{array}$ \\
\hline
\end{tabular}




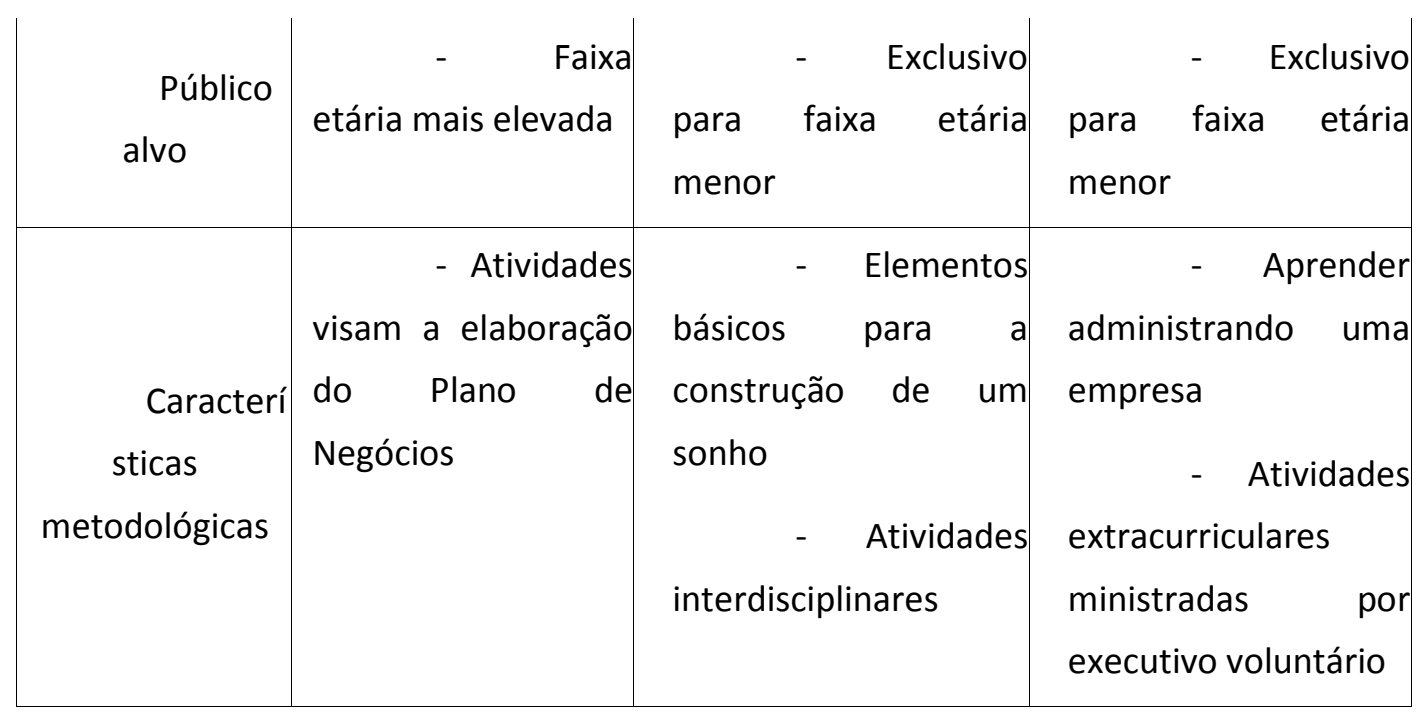

Ao analisar o quadro 1 proposto por (Pires, 2006), percebe-se que as propostas OE, PE e JA, apresentam diferentes características entre si. Dessa forma, faz-se necessário a elaboração de uma proposta híbrida, que respeite as particularidades do contexto onde está inserido o curso Técnico em Informática, na modalidade integrado.

\section{PropostaInfo@Empreendedor}

De acordo com (Dolabela, 2003) apud (Luz e Cêa, 2006, p. 84) empreendedor é aquele capaz de gerar novos conhecimentos por meio de "saberes" sintetizados nos pilares da educação: aprender a saber, aprender a fazer, aprender a conviver e aprender a ser.

Os pilares da educação citados por Dolabela corroboram as idéias colocadas por (Duarte, 2001, p. 36 - 37) ao comentar os princípios valorativos para a educação, exigidos pela sociedade contemporânea:

(1) "são mais desejáveis as aprendizagens que o indivíduo realiza por si mesmo, nas quais está ausente a transmissão por outros indivíduos de conhecimentos e experiências"; (2) "é mais importante o aluno desenvolver um método de aquisição, elaboração, descoberta, construção de conhecimento, do que esse aluno aprender os conhecimentos que foram descobertos e elaborados por outras pessoas"; (3) "a atividade do aluno, para ser verdadeiramente educativa, deve ser impulsionada e dirigida pelos interesses e necessidades da própria criança"; (4) "a educação deve preparar os indivíduos para acompanharem a sociedade em acelerado processo de mudança". 
Para que os objetivos exigidos da educação sejam realmente atingidos, faz-se necessário que os professores assumam uma posição diferenciada da que hoje é tida por muitos profissionais da educação. Insistir em aulas teóricas, apenas com o repasse de informações, não é mais suficiente para atingir e motivar os alunos. É preciso contextualizar, mostrar aos estudantes que conhecer é algo muito além do apenas ouvir informações, que conhecer de fato implica em busca, em desenvolvimento, em proposta de soluções, em análise de resultados, onde os professores são orientadores nesse processo e não entidades detentoras de todo o saber existente.

A proposta metodológica Info@Empreendedor, apresentada nesse trabalho, tem como público alvo estudantes da quarta série do curso Técnico em Informática, modalidade integrado. Nessa proposta, os alunos são convidados a "sair" da sala de aula, a conhecer o mundo do trabalho e oferecer soluções à empresas da sociedade, contribuindo com o fortalecimento da cultura da informática, sem perder o foco da importância de ações responsáveis para o bem das gerações futuras. Busca levar os alunos a perceber as particularidades, as dificuldades, e quão interessante é o mundo do trabalho que os espera. Nesse processo, os alunos devem demonstrar iniciativa, liderança e responsabilidade, muitas vezes agindo sobre pressão e tendo o trabalho em equipe como pilar para a apresentação das soluções.

A proposta metodológica Info@Empreendedor tem seu fundamento nas propostas para a educação empreendedora citadas em (Pires, 2006), que são a Oficina Empreendedora, a Pedagogia Empreendedora e o projeto Projeto Junior Achievement. Buscando contextualizá-la para educação empreendedora buscou-se características que estivessem de acordo com a realidade do educando, sua cultura, seus sonhos, seu ambiente e a comunidade onde está inserido. O quadro 2 apresenta as principais características da proposta metodológica Info@Empreendedor (I@E) e sua fundamentação. O quadro 3 apresenta as atividades detalhadas da proposta I@E.

Quadro 2: Proposta para Educação Empreendedora -

Info@Empreendedor(I@E)

\begin{tabular}{|l|l|l|}
\hline Características & \multicolumn{1}{|c|}{ I@E } & Fundamentação \\
\hline & $\begin{array}{l}\text { (1) Preparar os alunos para serem } \\
\text { empreendedores em todas as atividades } \\
\text { realizadas; }\end{array}$ & - OE \\
Objetivos \\
declarados & $\begin{array}{l}\text { (2) Desenvolver o protagonismo do aluno; } \\
\text { (3) Preparar o aluno para a possibilidade de } \\
\text { abertura de uma empresa; } \\
\text { (4) Desmistificar o processo de }\end{array}$ & \\
\hline
\end{tabular}




\begin{tabular}{|l|l|l|} 
& $\begin{array}{l}\text { informatização de micro e pequenas } \\
\text { empresas; } \\
\text { (5) Disseminar na comunidade a cultura da } \\
\text { informatização ética e responsável. }\end{array}$ & \\
\hline Público alvo & $\begin{array}{l}\text { Destinada a alunos do ensino médio } \\
\text { integrado. }\end{array}$ & - PE \\
\hline Características & $\begin{array}{l}\text { (1) Atividades interdisciplinares; } \\
\text { metodológicas }\end{array}$ & $\begin{array}{l}\text { (2) Aprender gerenciando um projeto de } \\
\text { desenvolvimento de software; } \\
\text { porecutivo voluntário; } \\
\text { (4) Elaboração de um plano de negócios } \\
\text { para a área da informática. }\end{array}$ \\
\hline
\end{tabular}

Para que as atividades listadas no quadro 3 possam ser de fato executadas e levem à conquista dos objetivos listados no quadro 2 , faz-se necessário atividades interdisciplinares, tendo em vista o exposto por (Pires, 2006, p. 23),

"As relações educacionais deveriam ser favoráveis ao desenvolvimento dos educandos para as demandas da sociedade, tornando-os cidadãos capazes de lidar com problemas criativamente, com liderança, visão de futuro, proatividade, dinamismo, empreendedorismo, criticidade, além de espírito de cooperação e de coparticipação. Para que isso possa ocorrer, os vários conteúdos necessariamente deixam sua condição de disciplinas isoladas e passam a trabalhar em conjunto, englobados em áreas de conhecimento de caráter contextualizador, o que se concretiza via interdisciplinaridade".

Quadro 3: Atividades a serem desenvolvidas para a execução da proposta I@E

\section{Atividades}

(1) Identificação de empresa parceira para o desenvolvimento de software ou melhoria de sistemas já implantados;

(2) Realização da coleta dos requisitos;

(3) Realização da análise essencial dos requisitos levantados; 
(4) Elaboração de protótipos do sistema;

(5) Desenvolvimento do software ou melhoria em sistemas já implantados, com base nos requisitos e protótipos elaborados;

(6) Apresentar aos professores, colegas e empresa parceira a análise essencial e o software desenvolvido ou melhorado/adaptado;

(7) Elaboração de um plano de negócios para empreendimento em informática.

A proposta I@E envolve as disciplinas Linguagem de Programação, Internet e Programação Web, Banco de Dados, Análise e Projetos, Sociologia e Filosofia. O quadro 4 apresenta as disciplinas envolvidas e sua contribuição para a execução da proposta I@E.

Quadro 4: Disciplinas envolvidas e sua contribuição para a execução da proposta I@E

\begin{tabular}{|c|c|}
\hline Disciplina & Contribuição \\
\hline Análise e Projetos & - Gerência de Projetos; \\
& - Coleta e análise de requisitos; \\
& - Prototipação. \\
\hline Linguagem de & - Desenvolvimento \\
\hline Programação & modificação/adaptação em software. \\
\hline Internet e & ou \\
\hline Programação Web & modificação/adaptação em software web. \\
\hline Banco de Dados & - Armazenamento de dados; \\
& - Elaboração de consultas. \\
\hline Filosofia & - Valores morais e éticos; \\
& - Ética em informática. \\
\hline Sociologia & - Evolução social e econômica. \\
\hline
\end{tabular}

As disciplinas listadas no quadro 4 estão envolvidas de forma interdisciplinar durante a execução da proposta I@E, no entanto, elas não são suficientes para atingir todos os objetivos 
apresentados no quadro 2. Assim, faz-se necessário a busca por parcerias com profissionais e entidades não ligadas diretamente ao curso Técnico em Informática modalidade integrado. Dessa forma, parcerias são firmadas para a realização de palestras e oficinas, tendo como foco a elaboração de plano de negócios e informações sobre a abertura de empresas, visando dessa forma, que os alunos expandam seus horizontes, visualizem a possibilidade da abertura de seu próprio empreendimento para a prestação de serviços na área da informática.

\section{Projeto piloto e seus resultados}

Durante o primeiro semestre do ano letivo de 2008 um projeto piloto da proposta metodológica Info@Empreendedor foi realizado. Tal projeto envolveu apenas a disciplina Análise de Projetos, assim, as atividades foram remodeladas bem como os conteúdos a serem trabalhados. As atividades realizadas durante o projeto piloto estão apresentadas no quadro 5.

Quadro 5: Descrição das atividades a serem realizadas pelos alunos durante o projeto piloto.

\begin{tabular}{|l|}
\hline \multicolumn{1}{c|}{ Atividades realizadas } \\
\hline - Identificação, por parte dos alunos previamente divididos em equipes, \\
de uma empresa que não possui nenhum software para auxílio na execução de \\
processos rotineiros, ou, identificação de necessidades em relação a softwares em \\
uma empresa já informatizada; \\
- Realização da coleta dos requisitos; \\
- Realização da análise essencial dos requisitos; \\
- Elaboração dos protótipos do sistema; \\
- Apresentação aos professores, colegas e empresa parceira a análise essencial e \\
os protótipos elaborados.
\end{tabular}

As atividades realizadas pelos alunos durante o projeto piloto foram supervisionadas pela professora da disciplina Análise e Projetos, autora desse trabalho. Tal projeto envolveu 30h/a, divididas em 5 momentos. Durante as aulas conteúdos da disciplina Análise e Projetos foram apresentados aos alunos, sendo também reservados momentos para discussões e realização de atividades dentro das próprias equipes. O detalhamento das atividades realizadas em cada um dos 5 momentos são listadas no quadro 6. Cada equipe possuía um gerente de projetos, um aluno escolhido pelos demais, responsável por gerenciar todas as atividades de seus colegas de equipe, 
bem como o andamento das atividades realizadas por ela. Algumas atividades foram realizadas pelos alunos em períodos extra-classe.

Quadro 6: Detalhamento das atividades do projeto piloto

\begin{tabular}{|c|c|}
\hline Momento & Atividades \\
\hline 01 & $\begin{array}{l}\text { - As informações gerais do projeto foram repassadas aos } \\
\text { estudantes. } \\
\text { - Equipes foram criadas. Os alunos foram orientados a não criar as } \\
\text { equipes apenas por afinidade e sim, pela disponibilidade dos mesmos, } \\
\text { tendo em vista a necessidade de atividades extra-classe para a realização do } \\
\text { projeto. } \\
\text { - Após a definição das equipes, os alunos elegeram um colega para } \\
\text { desempenhar o papel de gerente de projetos. Os alunos foram encorajados } \\
\text { a refletir sobre a escolha, para que o aluno eleito como gerente } \\
\text { demonstrasse, de fato, características e responsabilidades necessárias para } \\
\text { o desempenho do papel. } \\
\text { - As características necessárias para que uma determinada empresa } \\
\text { pudesse se tornar uma empresa parceira foram discutidas em sala. } \\
\text { - O formulário de contrato a ser assinado entre alunos e empresa } \\
\text { parceira foi entregue. } \\
\text { - O assunto ética em informática foi trabalhado da seguinte forma: } \\
\text { cenários reais foram entregues, as equipes foram convidadas a discutir tais } \\
\text { cenários e os apresentar para a classe, identificando se os mesmos são } \\
\text { exemplos de atitudes éticas ou não éticas, justificando suas conclusões e } \\
\text { convidando os demais alunos a contribuir. }\end{array}$ \\
\hline & $\begin{array}{l}\text { - Principais técnicas para coleta de requisitos foram apresentadas } \\
\text { aos alunos através de textos que expressam cenas encontradas na citada } \\
\text { fase de desenvolvimento de software. Os grupos foram convidados a } \\
\text { representar através de um breve teatro as cenas estudadas, destacando } \\
\text { atitudes adequadas e inadequadas. } \\
\text { - As equipes tiveram, em sala de aula, momento reservado para } \\
\text { preparar o planejamento para a coleta de requisitos na empresa parceira. } \\
\text { - As equipes foram convidadas a apresentar para a classe como } \\
\text { estava o desenvolvimento das atividades propostas junto a empresa }\end{array}$ \\
\hline
\end{tabular}


parceira.

- A arcabouço teórico sobre análise essencial de requisitos foi repassado aos alunos através de textos que foram explorados através de leitura e discussões.

- Utilizando o quadro-negro e televisão multimídia os elementos que 03 fazem parte da análise essencial foram apresentados aos alunos. Os alunos foram convidados a realizar exercícios para a fixação do conteúdo.

- Momento destinado para reunião das equipes.

- As equipes foram convidadas a apresentar para a classe como estava o desenvolvimento das atividades propostas junto a empresa parceira.

- A arcabouço teórico sobre prototipação de requisitos foi repassado aos alunos através de textos que foram explorados através de leituras e discussões.

04

- Em laboratório de informática, os alunos desenvolveram o(s) protótipo(s) dos requisitos da empresa parceira.

- As equipes foram convidadas a apresentar para a classe como estava o desenvolvimento das atividades propostas junto a empresa parceira.

- Os alunos apresentaram, no auditório da instituição de ensino, o trabalho realizado para a professora da disciplina, professores convidados, representantes da empresa parceira e demais colegas da classe. Cada equipe deveria apresentar o processo de desenvolvimento das atividades, bem como uma proposta de produto de software, através de protótipos. Foram 05 entregues à professora responsável pela disciplina atas de reuniões e documento adaptado da especificação de requisitos.

- Os alunos foram convidados ao relato de experiências, bem como a avaliar a atividade realizada.

- Considerações finais sobre o desenvolvimento do projeto foram feitas pela professora. 
Para a execução do projeto seis equipes foram formadas e firmaram parcerias com empresas de pequeno porte: uma loja de confecções, uma loja de equipamentos automotivos, uma oficina mecânica, uma lan-house, uma creche e uma revenda de purificadores de água.

Cinco das seis equipes obtiveram sucesso em seus resultados. Duas delas se comprometeram em ir além do projeto piloto e desenvolver o software em sua totalidade, seguindo padrões da engenharia de software e implantá-los nas empresas parceiras, essa opção foi feita visualizando uma possível oportunidade impulsionadora para a abertura de seu próprio empreendimento na área de informática. Quatro das cinco equipes que obtiveram sucesso relataram ter percebido a relação existente entre as diferentes disciplinas presentes na matriz curricular do curso. Os alunos que desempenharam o papel de gerente de projetos relataram ter sentido o "peso" da sua função, sendo que dois deles afirmaram ter sido difícil separar a amizade em alguns momentos. Os alunos não gerentes, por sua vez, afirmaram ter sido positiva a atuação dos gerentes. No entanto, uma das seis equipes não obteve sucesso. $\mathrm{O}$ aluno gerente de projetos não confiou tarefas aos demais colegas, não havendo assim envolvimento e trabalho em equipe. Por não ter delegado funções e não ter aceito sugestões, o gerente sobrecarregado, conseguiu cumprir apenas a etapa de coleta de requisitos. $\mathrm{O}$ episódio ocorrido com a equipe que falhou é visto como algo positivo, pois percebeu-se que toda classe aprendeu com essa experiência. Vários foram os comentários e discussões acerca do assunto.

Em sua maioria, os alunos demonstraram autonomia, responsabilidade e capacidade para trabalhar em equipe. Além de perceber a relação entre as diferentes disciplinas demonstraram ter apreendido não só conteúdos da disciplina de Análise e Projetos mas também de outras disciplinas, tendo sido estimulados a buscar novos conhecimentos.

Outro resultado positivo está relacionado ao fator confiança. Percebeu-se que a confiança entre alunos $x$ alunos e alunos $x$ professora foi fortalecida, aspecto que se fez fundamental para 0 desenvolvimento das atividades.

Mesmo o projeto piloto tendo sido aplicado de forma parcial, envolvendo apenas uma disciplina, acredita-se que os objetivos da proposta metodológica foram alcançados, pois houve o estímulo as características empreendedoras dos alunos e os mesmos demonstraram ter percebido a necessidade da sua atuação no mundo do trabalho, de forma cidadã e responsável, levando aos diferentes estratos do mercado soluções de TI de qualidade.

\section{Considerações Finais}

A proposta metodológica Info@Empreendedor consiste em um conjunto de atividades interdisciplinares elaboradas tendo como premissa as fundamentações empreendedoras, onde os 
alunos são convidados a deixar a sala de aula e, além de aplicar os conhecimentos teóricos adquiridos em seis disciplinas ofertadas durante a quarta série do curso técnico em informática, ter contato com a realidade do mundo do trabalho.

A aplicação da I@E, mesmo parcial, favoreceu o estímulo a características empreendedoras nos alunos do curso técnico em informática, despertando neles a percepção da necessidade de se tornarem cidadãos capazes de modificar o ambiente onde estão inseridos, visando a melhoria na qualidade de vida dos indivíduos que estão em seu entorno, através de soluções de $\mathrm{Tl}$ adequadas e com qualidade.

A vivência no mundo do trabalho proporcionou aos alunos visualizar possibilidades, particularidades e dificuldades desse ambiente. Estimulou-os a resolver problemas aplicando conceitos discutidos em sala de aula, com iniciativa e criatividade, trabalhando em equipe e assim aceitando as diferenças com comprometimento e responsabilidade. Espera-se que tal proposta metodológica possa, de fato, contribuir com a sociedade desmistificando o processo de informatização nas empresas de pequeno porte. Espera-se também que tal proposta possa contribuir para a abertura de empresas de prestação de serviços em informática por parte dos alunos participantes do projeto.

\section{Referências}

Bini, E. M. A Tecnologia da Informação na pequena empresa: um plano para diagnóstico e implantação. In: I Congresso de Ciência da Computação e Sistemas de Informação, Anais. UFLA: Universidade Federal de Lavras. 2007.

Dolabela, F. A ponte mágica: como Luísa, aos 11 anos, cria sua primeira empresa para realizar seu sonho. São Paulo: Mirian Paglia Editora de Cultura. 2004.

Dolabela, F. Pedagogia Empreendedora. Editora Cultura. São Paulo - SP. 2003.

Duarte, N. As pedagogias do aprender a aprender e algumas ilusões da assim chamada sociedade do conhecimento. Revista Brasileira de Educação, n. 18, set/out/nov/dez 2001. 2001.

Luz, A. S. , Cêa, G. S. S. Reflexões sobre a idéia do empreendedorismo na educação. Revista de Educação Educere et Educare, vol 1, no 1, jan/jun 2006, p. 83 - 87. 2006.

Pires, A. A. M. Empreendedorismo, protagonismo e pedagogia de projetos: uma simbiose transdisciplinar. Belo Horizonte, 2006, 206 f. Dissertação (Mestrado em Tecnologia) - Centro Federal de Educação Tecnológica de Minas Gerais - CEFET - MG. 2006. 
Elena Mariele Bini: Mestranda em Ensino de Ciência e Tecnologia pela UTFPR - Campus Ponta Grossa, professora da Faculdade Guairacá e também pertencente ao quadro próprio do magistério do Estado do Paraná. elena_bini@yahoo.com.br

Luis Mauricio Martins de Resende: professor do programa de mestrado em Ensino de Ciência e Tecnologia da UTFPR - Campus Ponta Grossa. Imresende@utfpr.edu.br

Rosemari Monteiro Castilho Foggiatto Silveira: professora do programa de mestrado em Ensino de Ciência e Tecnologia da UTFPR - Campus Ponta Grossa. castilho@utfpr.edu.br 